\title{
Anterior spinal cord infarction in a 77-year-old male after a right hemicolectomy: A case report
}

\author{
Benefsha Mohammad*1, Emilia Krol ${ }^{1}$, Charles B. Walsh ${ }^{2}$ \\ ${ }^{1}$ Danbury Hospital, Danbury, USA \\ ${ }^{2}$ Department of General Surgery, Danbury Hospital, USA
}

Received: February 15, 2016

Accepted: March 22, 2016

Online Published: April 14, 2016

DOI: $10.5430 /$ jer.v2n2p81

URL: http://dx.doi.org/10.5430/jer.v2n2p81

\begin{abstract}
A 77-year-old man underwent an exploratory laparotomy and right hemicolectomy for bowel ischemia. An etiology that has been investigated was hypotension leading to hypoperfusion. Intraoperatively, the patient experienced hypotension with a decline in mean arterial pressure from $150 \mathrm{mmHg}$ to $30 \mathrm{mmHg}$ for a duration of 20 minutes. Postoperatively the patient had another episode of hypotension with a decline in mean arterial pressure from $80 \mathrm{mmHg}$ to $55 \mathrm{mmHg}$ for a-15-minute period. On post-operative day three the patient was paraplegic with spinal cord infarction seen on magnetic resonance imaging from T10 to the conus medullaris. The blood supply to this region appeared unobstructed on imaging and therefore it is likely that intermittent hypotension was associated with insufficient blood flow to this region.
\end{abstract}

Key Words: Adamkiewicz, Spinal cold ischemia, Spinal cord infarction, Hypoperfusion, Paraplegia, Hypotension, Atherosclerosis, Exploratory laparotomy

\section{INTRODUCTION}

Spinal cord infarction is a rare condition with severe neurological symptoms and poor prognosis. This presentation accounts for only $1 \%$ of all strokes. ${ }^{[1,2]}$ Aside from a few retrospective studies and case reports, this condition has not been investigated as thoroughly. It has been most commonly described as a complication of aortic intervention and spinal cord hypoperfusion. ${ }^{[3-5]}$

We report the occurrence of anterior spinal artery syndrome in a 77-year-old gentleman who underwent an open general surgical procedure for acute bowel ischemia.

\section{CASE}

A 77-year-old male with history of hypertension, hyperlipidemia, end-stage renal disease on peritoneal dialysis, gastroe- sophageal reflux disease, depression, cirrhosis and coronary artery disease $\mathrm{s} / \mathrm{p}$ coronary artery bypass grafting presented to the Emergency Department with three days of abdominal pain and nausea. He underwent a computerized tomography (CT) scan of the abdomen and pelvis with results concerning for possible right-sided bowel ischemia. However, the laboratory values and clinical exam were unremarkable. His vital signs revealed a temperature of 98.2 degrees Farenheit, pulse of 100, blood pressure $96 / 44 \mathrm{mmHg}$, oxygen saturation of 96 percent on room air and weight of $77.6 \mathrm{~kg}$. On physical exam, he had minimal abdominal tenderness on the bilateral lower quadrants with questionable guarding and no rebound. Laboratory data showed sodium level of $141 \mathrm{mmol} / \mathrm{L}$, potassium 5 $\mathrm{mmol} / \mathrm{L}$, chloride $91 \mathrm{mmol} / \mathrm{L}$, bicarbonate $24 \mathrm{mmol} / \mathrm{L}$, blood urea nitrogen $59 \mathrm{mg} / \mathrm{dl}$, creatinine $10.9 \mathrm{mg} / \mathrm{dl}$, glucose 201

*Correspondence: Benefsha Mohammad, MD; Email: Benefsha.Mohammad@wchn.org; Address: Danbury Hospital, Danbury, USA. 
$\mathrm{mg} / \mathrm{dl}$, white blood cell count $17.7 \mathrm{k} /$ cumm, hemoglobin 12.7 $\mathrm{g} / \mathrm{dl}$, hematocrit $39 \%$, platelet $186 \mathrm{k} / \mathrm{cumm}$ and lactate 2.5 $\mathrm{mmol} / \mathrm{L}$. On hospital day-three, despite fluid resuscitation, the patient developed worsening abdominal pain, distention and a lactate level of 4.5. With this sudden change in his clinical status he was taken to the operating room for an exploratory laparotomy.

The patient received general anesthesia with propofol and rocuronium. At the start of the procedure the patient's blood pressure was close to his baseline at $170 / 80 \mathrm{mmHg}$. Within a few minutes into the case the patient experienced hemodynamic fluctuations in blood pressure and mean arterial pressure (MAP) that lasted for approximately 20 minutes. There was a decline in blood pressure and MAP, from 170/85 $\mathrm{mmHg}$ to $65 / 45 \mathrm{mmHg}$ and 130 to $50 \mathrm{mmHg}$, respectively. During this period the systolic blood pressure ranged from 65 to $155 \mathrm{mmHg}$ with diastolic pressures between $45 \mathrm{mmHg}$ and $55 \mathrm{mmHg}$ with nadir of $20 \mathrm{mmHg}$. The MAP ranged from $50 \mathrm{mmHg}-70 \mathrm{mmHg}$ with a nadir of $30 \mathrm{mmHg}$. After resuscitation with 2.2 liters of normal saline and two units of packed red blood cells for an estimated blood loss of $350 \mathrm{cc}$ the patient returned to his preoperative baseline blood pressure of 175/70 $\mathrm{mmHg}$ and MAP of $70 \mathrm{mmHg}$. On exploration of the abdominal cavity patient was found to have patchy areas of ischemia in the cecum, without transmural necrosis or perforation. Right hemicolectomy with primary anastomosis was performed. The remainder of the procedure was uneventful. His estimated blood loss at the end of the procedure was about $350 \mathrm{cc}$.

Due to decreased respiratory effort the patient was maintained on ventilation and transferred to the ICU for close monitoring. He remained stable in the ICU overnight without any significant changes in his hemodynamics. He received subcutaneous heparin 5000 three times daily for DVT prophylaxis. On post-operative day one he was taken to the operating room for placement of tunneled hemodialysis catheter. At the start of the case the patient's blood pressure was $120 / 78 \mathrm{mmHg}$. However, within the next 15 minutes his blood pressure and MAP steadily declined. His systolic blood pressure declined from 95 to $90 \mathrm{mmHg}$, diastolic pressure from 70 to $30 \mathrm{mmHg}$ and MAP from $80 \mathrm{mmHg}$ to approximately $55 \mathrm{mmHg}$. With IV resuscitation with one liter normal saline his blood pressure returned to $100 \mathrm{~s} / 50 \mathrm{~s}$ $\mathrm{mmHg}$ and MAP of $70 \mathrm{~s}$ to $80 \mathrm{~s} \mathrm{mmHg}$. He did not have any other such significant changes in his blood pressure for the remainder of the case. He was successfully extubated on post-operative day 0 . His post-operative course was further complicated by new onset Atrial Fibrillation with rapid ventricular response that required metoprolol $5 \mathrm{mg}$. By the time of discharge the patient was in sinus rhythm.
On post-operative day three from the initial procedure, the patient complained of bilateral lower extremity weakness. On physical exam he was found to have decreased bilateral lower extremity strength and decreased sensory perception in his feet as well as anterior shins that subsequently progressed to complete lower extremity paraplegia. A neurology consult was placed and an MRI was obtained. The MRI revealed hyperintense signals and cord expansion as high as T7 but most prominent from $\mathrm{T} 10$ to L1 as well as cord expansion at the conus medullaris (see Figure 1). This was consistent with spinal cord infarction possibly secondary to embolism of the artery of Adamkiewicz, which would result in a similar distribution of cord ischemia. The patient received a full work-up of the ischemic event to rule out thromboembolic causes. A transthoracic echocardiogram was obtained which showed EF of 55\%-60\%, mild left atrial enlargement, mild diastolic dysfunction and increase in wall thickness by 1.3 $\mathrm{cm}$. This was unchanged. CT angiography of the chest and abdomen revealed severe atherosclerotic disease of the thorax and abdomen without any signs of aneurysm, dissection or major vessel occlusion. The patient was started on aspirin and Plavix as recommended by the neurologist. Physical therapy was also initiated. He was eventually discharged to the inpatient rehabilitation unit, however, despite intensive physical therapy the patient continued to have paraplegia without any neurological improvement.

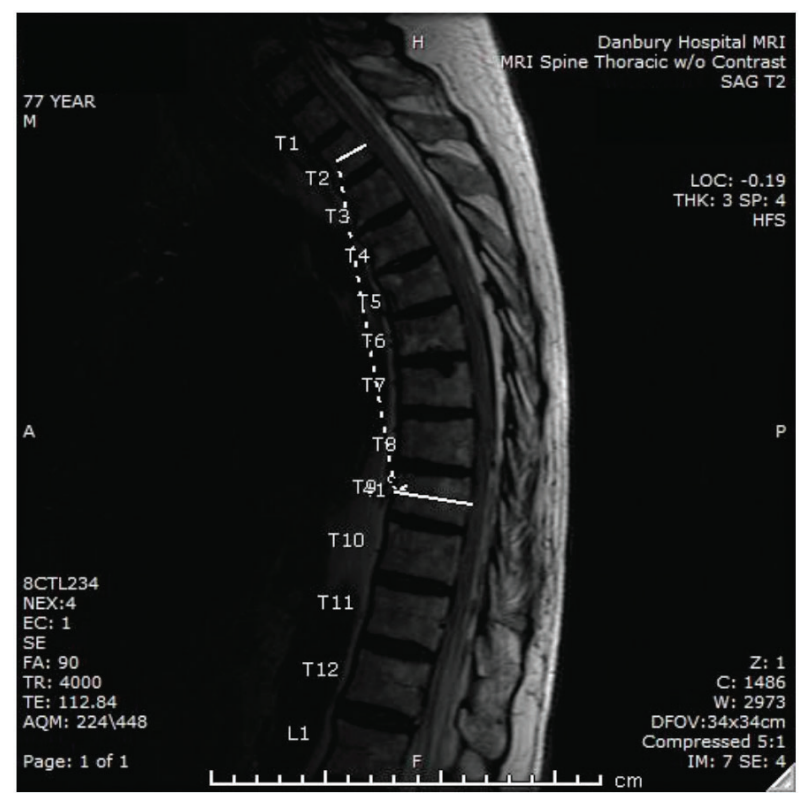

Figure 1. Sagittal MRI showing hyperintense signaling from T10 to the conus medullaris

\section{DiscuSSION}

Three longitudinal arteries supply the spinal cord: the anterior spinal artery, the two posterior spinal arteries and anas- 
tomoses between the three. The artery of Adamkiewicz is the largest segmental artery arising from the aorta at variable sites and supplies the lower two thirds of the spinal cord via the anterior spinal artery. Injury to this artery can result in anterior spinal cord syndrome which accounts for about $5 \%$ to $8 \%$ of all acute myelopathies. The symptoms are sudden and severe with complaints of back pain, loss of bowel and bladder control and most significantly paraplegia. Most patients also have some sensory disturbance.

As seen on the MRI, the injury that occurred was in the distribution of the artery of Adamkiewicz. The injury was likely due to an ischemic event however; the exact etiology cannot be stated with certainty. It is not very likely the surgical procedure could have resulted in damage to the aorta or internal iliac arteries to lead to such injury. Another possibility could be a thromboembolic phenomenon since the patient had developed new onset atrial fibrillation. Angiography ruled out the possibility of a thrombus, but the possibility of an atherosclerotic event could not be ruled out.

Ischemia secondary to hypotension can also serve as another etiology. Brief hypotension secondary to anesthesia or cardiovascular events has been linked to ischemia of the spinal cord, specifically in the anterior spinal artery distribution, in many other cases. ${ }^{[3,4]}$ However, one retrospective study of 145 cases, found that 66 patients suffered cord injury from transient global ischemia secondary to hypotension or cardiac arrest. ${ }^{[4]}$ The majority of the specimens showed more severe neuronal injury in the anterior horn nuclei in the lower thoracic and lumbosacral region with much as $95.5 \%$ of specimens showing ischemia in the lumbosacral cord. ${ }^{[5]}$ In one case study a 19-year-old female underwent induced hypotension under general anesthesia resulting in spinal cord infarction from $\mathrm{T} 9$ to the conus medullaris similar to our pa- tient. Hypotension was maintained with systolic BP between 70 to $80 \mathrm{mmHg}$ and diastolic pressures between 35 and 25 $\mathrm{mmHg}$. The MAP was maintained between 50 and $55 \mathrm{mmHg}$ similar to our patient. However in this case, the patient was hypotensive for 2.5 hours and our patient's hypotension was transient lasting for only minutes. Though other studies have shown no statistically significant correlation between duration of hypotension and degree of spinal cord injury. ${ }^{[6]}$ The reason for this is that the severity of injury depends on both the duration and depth of ischemic injury. ${ }^{[6]}$ Evidence in support of this relationship has also been seen in other case reports. One case reported lower limb paralysis 24 hours after a cholecystectomy in which the patient developed transient hypotension with systolic BP in the $60 \mathrm{~s}$. In contrast, the same article reported a case of limb paralysis in a 51-year-old female who underwent cosmetic surgery for facial lift. In this case, the blood pressure declined to $47 \mathrm{mmHg}$ systolic and $25 \mathrm{mmHg}$ diastolic remaining at this level for 2.5 hours. ${ }^{[3]}$

Anterior spinal cord injury secondary to ischemia of the lower thoracic and lumbosacral region is rare. ${ }^{[7]}$ The reason for this is probably because these regions of the spinal cord have very good blood supply from the artery of Adamkiewicz. The midthoracic region of the spinal cord is considered the ischemic watershed zone based on anatomic studies and is thus considered most vulnerable to ischemia. ${ }^{[6,8,9]}$ However, the lower thoracic and lumbosacral spine have been shown to undergo neuronal injury even to transient ischemia form hypoperfusion secondary to hypotension. Many factors have been implicated to be the etiology behind ischemia leading to spinal cord injury, but none have been supported by significant statistical data. ${ }^{[10]}$ In our patient it was likely a synergistic effect from transient hypotension and severe atherosclerotic disease that lead to anterior spinal cord injury.

\section{REFERENCES}

[1] Novy J, Carruzzo A, Maeder P, et al. Spinal cord ischemia: clinical and imaging patterns, pathogenesis, and outcomes in 27 patients. Arch Neurol. 2006; 63(8): 1113-1120. PMid:16908737 http://dx.doi.org/10.1001/archneur.63.8.1113

[2] Wong J, Dufton J, Mior S. Spontaneous conus medullaris infarction in a 79 year-old female with cardiovascular risk factors: a case report. Journal of Canadian Chiropractic Association. 2012; 65(1): 58-65.

[3] Singh U, Silver JR, Welply NC. Hypotensive infarction of the spinal cord. International Medical Society of Paraplegia. 1994; 32: 314-322. PMid:8058348 http://dx.doi.org/10.1038/sc.1994.54

[4] Drummond JC, Roland RL, Erik LO. Spinal Cord Ischemia Occurring in Association with Induced Hypotension for Colonic Surgery. Anesthesia \& Analgesia. 2012; 114 (6): 1297-300.

[5] Plecha EJ, Seabrook GR, Freischlag JA, et al. Neurologic complications of reoperative and emergent abdominal aortic recon- struction. Ann Vasc Surg. 1995; 9: 95-101. PMid:7703069 http: //dx.doi.org/10.1007/BF02015322

[6] Duggal N, Lach B. Selective Vulnerability of the Lumbosacral Spinal Cord After Cardiac Arrest and Hypotension. Selective Vulnerability of the Lumbosacral Spinal Cord After Cardiac Arrest and Hypotension. Stroke. 2002; 33: 116-121. PMid:11779899 http://dx.doi.org/10.1161/hs0102.101923

[7] Nedeltchev K, Loher TJ, Stepper F, et al. Long-term outcome of acute spinal cord ischemia syndrome. Stroke. 2004; 35: 560565. PMid:14726546 http://dx.doi.org/10.1161/01.STR. 00 $00111598.78198 . \mathrm{EC}$

[8] Garcia JH. Morphology of global cerebral ischemia. Crit Care Med 1988; 16: 979-987. PMid:3048897 http://dx.doi.org/10.1097 /00003246-198810000-00009

[9] Sliwa JA, Maclean IC. Ischemic myelopathy: a review of spinal vasculature and related clinical syndromes. Arch Phys Med Reha- 
bil. 1992; 73: 365-372. http://dx.doi.org/10.1016/0003-9 993(92) $90011-\mathrm{K}$

[10] Masson C, Pruvo JP, Meder JF, et al. Spinal cord infarction: clin- ical and magnetic resonance imaging findings and short term outcome. Journal of Neurol Neurosurgery Psychiatry. 2004; 75: 14311435. PMid:15377691 http://dx.doi.org/10.1136/jnnp. 20 03.031724 